\title{
Gestão e Controle de Qualidade da Produção de Bioetanol
}

\author{
Management and Quality Control of Bioethanol Production \\ Michael Feroldi', Mateus Barbian Urio², Paulo André Cremonez ${ }^{3}$, \\ Amanda Viana de Araújo ${ }^{4}$, Joel Gustavo Teleken ${ }^{5}$
}

Universidade Federal do Paraná

\section{Resumo}

Por ser um grande produtor de cana de açúcar, destinada a produção de etanol, o Brasil se insere no mercado internacional na qualidade de exportações do produto. Para isso, o governo vem incentivando o setor de produção para que busquem a certificação de qualidade. O presente trabalho teve por objetivo explorar de maneira pratica e objetiva uma abordagem sobre os sistemas de gestão de qualidade, as regulamentações que regem as especificações e os métodos analíticos utilizados para garantir a qualidade do produto da indústria alcooleira. Pela produção de Bioetanol ser inerente a diversas variáveis que interferem em sua qualidade, é indispensável um controle rigoroso da sua produção e comercialização, para garantir maior confiabilidade ao mercado consumidor seja ele nacional ou internacional. A não conformidade com as exigências previstas por legislação pode gerar problemas de combustão, como a geração de borras, corrosão, redução de eficiência e vida útil do motor.

Palavras-chave:Culturas energéticas, biocombustíveis, energias renováveis.

\begin{abstract}
For being a large producer of sugarcane for the production of ethanol, Brazil is part of the international market as exports of the product. To this end, the Government has been encouraging the production sector to seek quality certification. The present study aimed to explore practical and objective way an approach on quality management systems, the rules governing the specifications and the analytical methods used to ensure the quality of the alcohol industry's product. By bioethanol production be inherent to several variables that interfere in its quality, evaluates essential a rigorous control of their production and marketing, to ensure greater reliability to the consumer market whether it is national or international. Non-compliance with the requirements laid down by legislation may generate problems of combustion, as the generation of Lees, corrosion, reducing efficiency and useful life of the engine.
\end{abstract}

Keywords: Energy crops, biofuels, renewable energy. 


\section{INTRODUÇÃO}

A busca por fontes renováveis e sustentáveis de energia, em virtude da problemática do cenário atual frente às emissões de gases-estufa (GEE), tem contribuído para a viabilização do comércio nacional e internacional do etanol, transformando-o em um importante fator de desenvolvimento econômico brasileiro, contudo, este deve estar ligado diretamente à garantia de sua qualidade para tal viabilização (Cortez, 2010).

O Brasil vem se destacando no setor sucroalcooleiro como um grande produtor de cana-de-açúcar que é destinada à produção de açúcar e etanol. O país também vem buscando se inserir no mercado internacional como um grande exportador, e para isto, vem incentivando o setor para que busquem a certificação de qualidade dos produtos e barrando, mediante fiscalização, a comercialização das usinas que ainda apresentem resistência quanto à adequação de seus produtos, o caso, o etanol (Oliveira et al., 2012).

Na década de 70, em plena crise mundial do petróleo, o governo criou o Programa Nacional de Produção de Álcool Combustível - PRÓ-ÁLCOOL, com o objetivo de impulsionar o início da amplitude nacional de produção de etanol carburante (álcool etílico hidratado) visando a substituição de combustíveis de origem fóssil, à época, largamente, importados pelo país. O programa contava com diversificados incentivos estatais, visando o emprego de mandioca como matéria-prima, a qual não deu resposta positiva ao que dela se esperava em termos de produção agrícola (Sobrinho, 2012).

A cana-de-açúcar (Saccharum officinarum L.), hoje amplamente cultivada nas regiões centro-sul e nordeste do Brasil (Cortez, 2010), foi responsabilizada na época de ser a matéria-prima principal a suprir a demanda de todo o setor sucroalcooleiro brasileiro. Até os dias atuais sua produção e área plantada aumentaram significativamente (Figura 1), pela sua importância energética na matriz energética renovável. Concomitantemente, a produção brasileira de etanol passou por crises de abundância, escassez e instabilidade de preços.

A região Nordeste do Brasil é relatada por possuir os primeiros engenhos brasileiros de canade-açúcar e a região Centro-Oeste é caracterizada como a maior área de expansão da cana. Porém, é a região Sul-Sudeste que detém da maior parte da produção nacional, cerca de 87\% (Cortez, 2010).

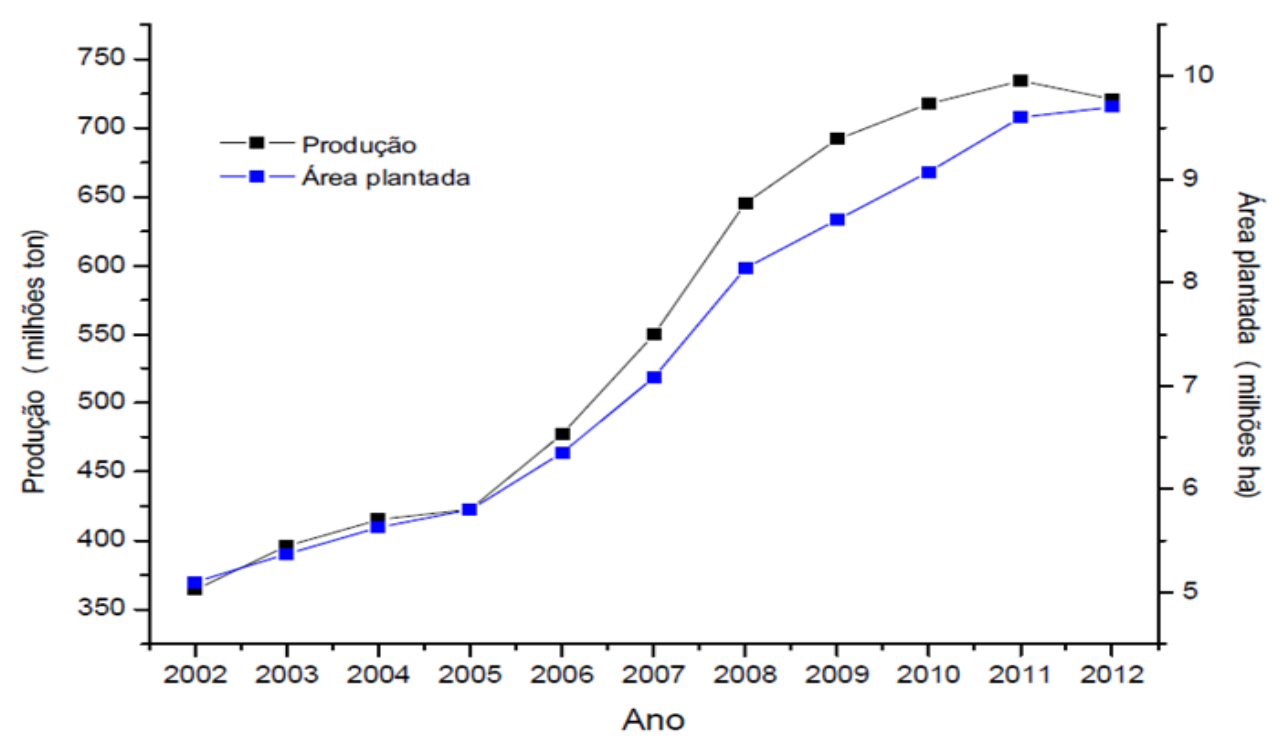

Figura 1 - Produção brasileira de cana-de-açúcar e área plantada. Fonte: FAO (2014).

A safra brasileira de cana 2012/2013 foi responsável pela produção de 21,36 bilhões de litros de etanol, conforme dados da UNICA (2013). O Paraná, neste período, se colocou como quinto colocado no ranking de produção de cana-de-açúcar, bem como de etanol.

Segundo Relatório da Universidade de Illinois (Chicago-EUA), o Brasil perdeu o posto de maior produtor de etanol do mundo para os Estados Unidos no ano de 2012. Porém não é o que indica os dados da FAO (2014), mostrando que o Brasil foi ultrapassado já em 2006 em produção de etanol (Figura 2). 


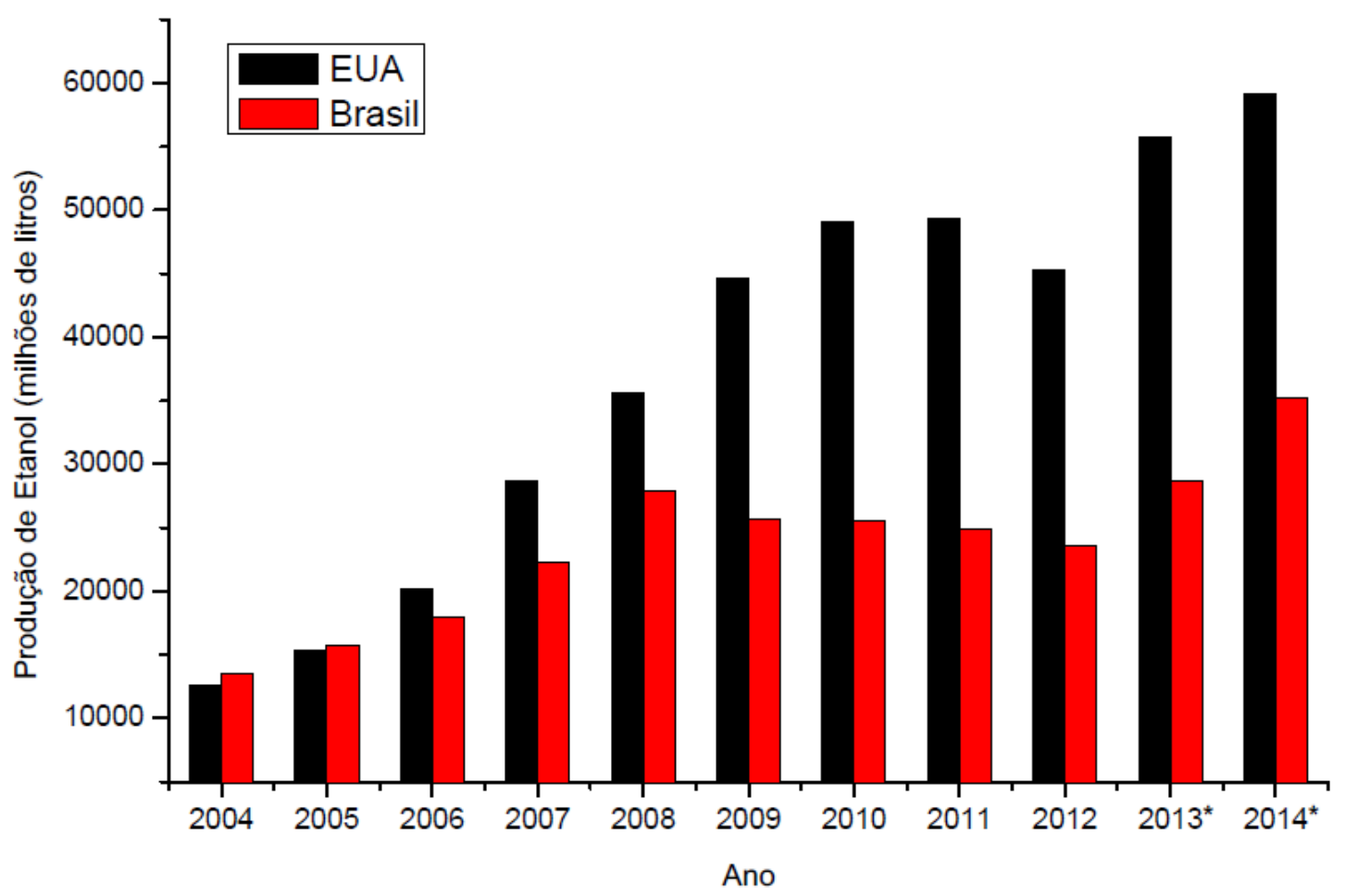

Figura 2 - Crescimento da produção de etanol no Brasil e EUA. *projeção 2013/2014. Fonte: FAO (2014).

Mesmo assim, o Brasil ganha no quesito custo de produção pelo fato de que os EUA se baseiam na produção de etanol a partir do amido de milho, que industrialmente requer maiores custos e tempo, visto que a produção é dada por rota enzimática e que estas enzimas não são recuperadas ao final do processo (Sobrinho, 2012). Porém a produção de etanol a partir do milho apresenta vantagens, quando empregando a biomassa residual na ração animal (Zafalon, 2012).

Devido à alta exigência aliada à maior consciência por parte dos consumidores, a qualidade é uma questão muito discutida e cobrada na atualidade. Portanto, a satisfação do cliente, bem como o próprio favorecimento interno da indústria, deve ser o ponto de partida para uma posição competitiva no mercado nacional e internacional. Sendo assim, a qualidade é pré-requisito para a sobrevivência de uma empresa, seja para este ou qualquer outro ramo de atividade (Hanny \& Rey-Sánchez, 2009).

Neste contexto, o presente trabalho visa demonstrar de maneira objetiva uma abordagem sobre os sistemas de gestão de qualidade, as regulamentações que regem as especificações e os métodos analíticos utilizados para garantir a qualidade do produto da indústria alcooleira.

\section{GESTÃO DE QUALIDADE}

Devido à alta exigência aliada à maior consciência por parte dos consumidores, a qualidade é uma questão muito discutida e cobrada na atualidade. Portanto, a satisfação do cliente, bem como o próprio favorecimento interno da indústria, deve ser o ponto de partida para uma posição competitiva no mercado nacional e internacional. Sendo assim, a qualidade é pré-requisito para a sobrevivência de uma empresa, seja para este ou qualquer outro ramo de atividade (Hanny \& Rey-Sánchez, 2009).

Uma adequada gestão dos recursos de produção confere uma importante vantagem competitiva à empresa que a realiza, que, dentre outras possibilidades, permite a rápida resposta às demandas do mercado, bem como um melhor desempenho operacional (Satolo, 2007).

A internacionalização de empresas depende da competição vinculada a uma boa infraestrutura tecnológica, cultural e empresarial, sendo a obtenção da certificação de conformidade de produto vista como um passaporte para esse processo. Esses fatores influenciam como estímulo ao país a gerar produtos e serviços que atendam cada vez mais o mercado consumidor (Ballestero-Alvarez, 2001). 
Conforme Barbará (2006), a ABNT (Associação Brasileira de Normas Técnicas) é o órgão responsável pela normatização da ISO/9000, seu conteúdo é de responsabilidade dos Comitês Brasileiros - CB, e dos Organismos de Normatização Setorial - ONS, diretamente ligados ao Instituto Nacional de Metrologia, Normatização e Qualidade Industrial - INMETRO.

A palavra ISO, segundo Ballestero-Alvarez (2001), tem como significado International Organization for Standardization, ou seja, Organização Internacional para a Padronização. Sediada em Genebra (Suíça), é uma organização não governamental que foi criada em 23 de fevereiro de 1947 com o objetivo de elaborar e aplicar padrões internacionais para a qualidade de diversos produtos.

A série ou família NBR 9000:2000 é formada pelas seguintes partes: NBR ISO 9000; NBR ISO 9001; NBR ISO 9004 e NBR ISO 19011 que governam o setor de comércio nacional e internacional. Estas padronizam de forma coerente o sistema de gestão da qualidade, com a finalidade de direcionar, conduzir e operar a organização de maneira transparente e sistemática (Barbará, 2006).

Marshall Júnior (2006) aponta que os clientes e a sociedade como um todo são beneficiados com a NBR ISO 9001, pois esta, melhora o relacionamento técnico e comercial com o fornecedor, aumenta a segurança e confiança dos bens e serviços adquiridos, o consumidor fica mais protegido, o desperdício e poluição são reduzidos e a empresa se promove no mercado consumidor, superando as barreiras da competitividade.

A NBR ISO 9001 visa abranger os processos de uma organização, com o objetivo de desenvolver, implementar e melhorar a eficácia de um sistema de gestão da qualidade, visando o aumento da satisfação do cliente, atendendo aos seus próprios requisitos (Hanny \& Rey-Sánchez, 2009).

Oito princípios da gestão de qualidade formam a base para as normas de sistema de gestão da qualidade da família ABNT NBR ISO 9000, são elas: foco no cliente, liderança, envolvimento de pessoas, abordagem de processo, abordagem sistêmica para a gestão, melhoria contínua, abordagem factual para tomada de decisão e benefícios mútuos nas relações com os fornecedores (ABNT NBR ISO 9000).

O Brasil, ao mesmo tempo que vem se destacando no setor sucroalcooleiro como um grande produtor de cana-de-açúcar que é destinada à produção de açúcar ou etanol, também vem buscando se inserir no mercado internacional como um grande exportador. Desta forma, o setor vem sendo incentivado à buscar a certificação de qualidade dos produtos e barrando, mediante fiscalização, a comercialização das usinas que ainda apresentem resistência quanto à adequação de seus produtos, no caso, o etanol (Oliveira et al., 2012).

Chiavenato (1999) aponta dois tipos de conceito de qualidade, sendo a interna e a externa. Enquanto a interna está relacionada à administração da qualidade dos processos, produtos e serviços de uma empresa, a externa constitui na visão do cliente, consumidor ou usuário a respeito do produto ou serviço que compra e utiliza.

Mais importante do que implantar um sistema de gestão de qualidade, é certificá-lo junto a ABNT, onde além do ganho de visibilidade frente ao mercado, possibilita a exportação para mercados mais exigentes, ou o fornecimento à clientes que requerem da organização, a capacidade de garantir a manutenção das características de seus produtos (Marshall, 2006).

À medida que os conceitos de gestão de qualidade foram se difundindo, foram criando-se também técnicas e ferramentas de qualidade as quais podem ser divididas em seis grandes grupos:

- Fluxo de produção: relacionadas a toda dinâmica do processo produtivo no que se refere a trocas físicas e o desenho de padrões;

- Organização e cultura: atribuídas à organização individual dos papéis, bem como ao aprendizado e comunicação;

- Controle de Processos: que visam o controle, estabilização e melhoria do processo de produção;

- Métricas: voltadas à recompensa para os times de trabalho e colaboradores a partir da análise de desempenho;

- Logística: que controlam os fluxos de materiais internos e externos e;

- Desenvolvimento de produtos: onde enquadram-se técnicas e ferramentas voltadas a diminuição de tempo e falhas nos processo de desenvolvimento de novos produtos (Feld, 2000; Satolo, 2007).

Indicadores de desempenho, sobretudo ligados a aspectos de qualidade são cada vez mais encontrados no setor industrial. O acompanhamento e a interpretação destes indicadores se tornam cada vez mais indispensáveis para a tomada de decisões a partir de fatos. Neste contexto, o Controle 
Estatístico de Processos (CEP) propicia a identificação de causas de variações em processos produtivos determinando o melhor momento em que uma ação deve ser iniciada (Caulcutt, 1996).

Independentemente da forma de como é conduzido, qualquer processo está sujeito a perturbações (Costa et al.,2005) sejam elas dependentes de causas aleatórias, inerentes ao processo, o qual consegue absorvê-la sem gerar produtos defeituosos, ou dependentes de causas atribuíveis, possuindo fontes de variação muito maiores que a variabilidade natural, sendo na maioria das vezes identificáveis. Quando um processo possui apenas variações de causas aleatórias, é considerado sob controle, já os que contém causas atribuíveis são considerados fora de controle (Montgomery, 2001).

Para analisar e monitorar o comportamento de determinadas variáveis do processo são utilizados então os gráficos de controle, onde observa-se os valores obtidos de uma amostra quanto a um determinado parâmetro, em relação aos limites de controle (Oliveira, 2011).

Os gráficos de controle (Figura 3) são constituídos por três linhas paralelas nomeadas Limite Superior de Controle (LSC), Linha Média (LM) e Limite Inferior de Controle (LIC). À medida que exista uma flutuação não aleatória, os valores obtidos em uma análise da amostra e plotados no gráfico tendem a extrapolar os limites, indicando assim, que o processo está fora de controle (Vieira, 1999).

Montgomery (2001) definiu um sistema fora de controle quando:

“- Um ponto se localiza fora dos limites de controle três sigma;

- Dois, em três pontos consecutivos, se localizam além dos limites de alerta de dois-sigma;

- Quatro, em cinco pontos consecutivos, se localizam além a uma distância de um sigma ou mais em relação à linha central;

- Oito pontos consecutivos se localizam de um mesmo lado da linha central."

Aliado aos gráficos de controle é comum calcular-se a Capacidade do Processo (Cpk), o qual revela se um processo é estável, ou seja, que está sob controle e é capaz de atender o nível de qualidade almejado para os produtos (Soares, 2003).

Contudo, o Controle Estatístico do processo não identificará as causas atribuíveis a tais variações, sendo este o papel dos gestores, que podem além de identificá-las, procurar eliminá-las do processo reduzindo desta forma a variabilidade do processo (Montgomery, 2001; Xie \& Goh, 1999).

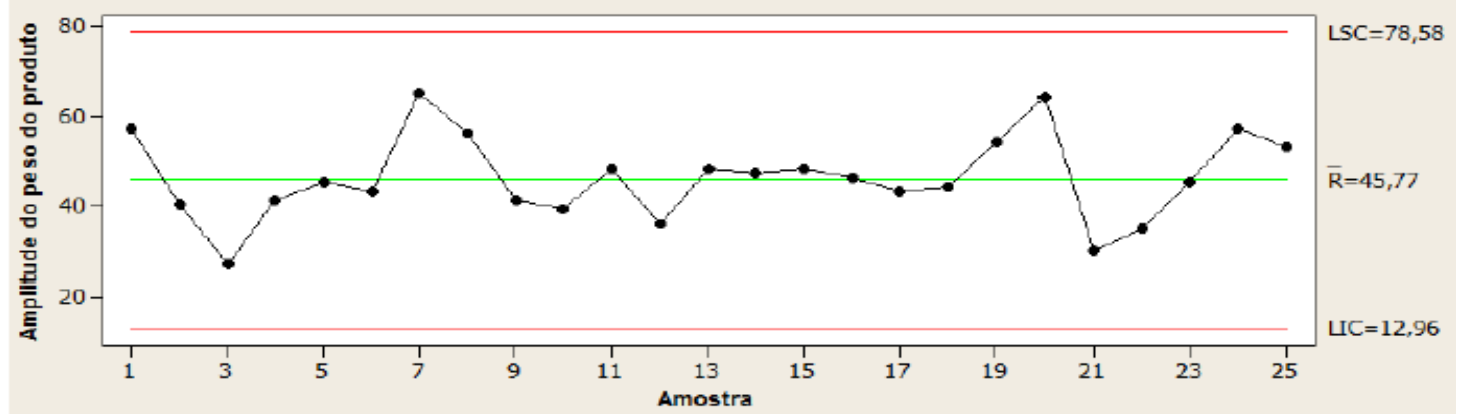

Figura 3 - Modelo de Gráfico de Controle. Fonte: Daminelli (2013).

\section{CONTROLE DE QUALIDADE}

Segundo o White Paper (2007), a produção, utilização e comercialização do etanol no Brasil são regidas pela ANP (Agência Nacional do Petróleo, Gás Natural e Biocombustíveis). A Resolução ANP $N^{\circ} 7 / 2011$ (alterada pela $N^{\circ} 7 / 2013$ ) é responsável por regularizar as especificações do etanol anidro combustível e etanol hidratado, em adição ao Regulamento Técnico n ${ }^{\circ} 3 / 2011$ da mesma agência, bem como responsável por apresentar e fiscalizar as obrigações acerca do controle de qualidade a serem atendidas pelos diversos setores envolvidos.

Etanol anidro combustível (EAC) deve ser produzido e comercializado respeitando os teores obrigatórios da ANP (2011b), que para o teor de etanol, deve ser no mínimo equivalente a 98\%. Já para o etanol hidratado combustível (EHC), este deve ser de 94,5, ambos em percentual volumétrico.

Além desse, diversos outros parâmetros (Tabela 1) devem ser rigorosamente fiscalizados e cumpridos a fim de se deter de um controle acerca do produto (etanol). 
Tabela 1 - Parâmetros de qualidade de etanol anidro (EAC) e etanol hidratado (EHC)

\begin{tabular}{lccc}
\hline Parâmetro & Unidade & EAC & EHC \\
\hline Aspecto & - & Límpido & Límpido \\
Cor & - & Laranja & Transparente \\
Acidez & $\mathrm{mg} \cdot \mathrm{L}^{-1}$ & 30 & 30 \\
Condutividade Elétrica & $\mu S \cdot \mathrm{m}^{-1}$ & 389 & 389 \\
Massa específica & $\mathrm{kg} \cdot \mathrm{m}^{-3}$ & 791,5 máx. & $807,6-811,0$ \\
Teor alcoólico & $\% \mathrm{v}$ & 99,6 mín. & $95,1-96,0$ \\
pH & - & - & $6,0-8,0$ \\
Etanol & $\% \mathrm{v}$ & 98 & 94,5 \\
Água & $\% \mathrm{v}$ & 0,4 & 4,9 \\
Metanol & $\% \mathrm{v}$ & 0,5 & 0,5 \\
Resíduo de Evaporação & $\mathrm{mg} \cdot 100 \mathrm{~mL}^{-1}$ & 5 & 5 \\
Goma lavada & $\% \cdot 100 \mathrm{~mL}^{-1}$ & 5 & 5 \\
Hidrocarbonetos & $\mathrm{mg}$ & 3 & 3 \\
Cloreto & $\mathrm{mg} \cdot \mathrm{kg}^{-1}$ & 1 & 1 \\
Sulfato & $\mathrm{mg} \cdot \mathrm{kg}^{-1}$ & 4 & 4 \\
Ferro & $\mathrm{mg} \cdot \mathrm{kg}^{-1}$ & 5 & 5 \\
Sódio & $\mathrm{mg} \cdot \mathrm{kg}^{-1}$ & 2 & 2 \\
Cobre & $\mathrm{mg} \cdot \mathrm{kg}^{-1}$ & 0,07 & - \\
\hline
\end{tabular}

Fonte: ANP (2011a).

Segundo o Regulamento Técnico n ${ }^{\circ} 3 / 2011$, apenas o etanol anidro combustível pode conter a adição de corantes, os quais também são determinados neste, e devem ser acompanhados pelos laboratórios certificados pela ANP (2011ab) quanto ao seu controle de qualidade. Estes corantes específicos devem, restritamente, estar no estado líquido, apresentar solubilidade apenas em etanol e coloração laranja específica.

Se comparado a outras agências de especificação como a ASTM (American Society for Testing and Materials) dos EUA e a EN (European Committee for Standardization), apenas a ABNT (Associação Brasileira de Normas Técnicas) possui especificações acerca do controle de densidade de etanol combustível, dispostos na NBR 5992 (2008). Este método é utilizado no Brasil para determinar o grau de pureza além de permitir uma verificação rápida, porém pouco precisa do teor de água presente (White paper, 2007).

Mesmo a ASTM e a CEN não especificando "sem impurezas", implicitamente pode ser observado a mesma descrição para as 3 normas (ANP, ASTM e CEN) em suas especificações acerca da coloração do combustível, a qual determina o etanol invariavelmente como límpido e transparente, subentendendo o termo anteriormente citado às agências internacionais (White Paper, 2007; ANP, 2011b).

Com relação à condutividade elétrica, este deve atender o limite de $389 \mu \mathrm{S} . \mathrm{m}^{-1}$ (micro Siemens por metro), respeitando a técnica especificada pela NBR 10547 (1998), sendo que esse deve fazer parte do Boletim de Conformidade referente ao produto comercializado. Este teste é obrigatório somente no Brasil, e é realizado no intuito de gerar resultados prévios e rápidos quanto à contaminação do etanol, que podem levar à corrosão de componentes dos motores veiculares (White Paper, 2007).

O teor de hidrocarbonetos é regularizado pela NBR 13993 (2002) e tem como limite máximo a presença de 3\% (v/v) em EAC e EHC. Segundo o White Paper (2007), a ANP é a única agência de especificações que controla os níveis de hidrocarbonetos, visto que na Europa e nos EUA, a utilização destes como agentes desnaturantes no etanol é muito frequente. 
Conforme Goldemberg et al. (2008), o uso de etanol em substituição à gasolina incide na mitigação do passivo ambiental referente às emissões de hidrocarbonetos em especial os aromáticos, pois são considerados de menor toxicidade, uma vez que apresentam menor reatividade atmosférica.

Coelho e colaboradores (2006) também apontam, dentre os efeitos mais significativos em relação ao uso de apenas $10 \%$ do volume da gasolina (E10), a redução significativa das emissões de compostos como o benzeno e o 1-3 butadieno, conhecidos como cancerígenos.

A certificação quanto à presença de cobre em etanol anidro somente é necessária quando este for transportado ou produzido em contato com equipamentos compostos ou simplesmente revestidos do material. O limite especificado no Regulamento Técnico ${ }^{\circ}$ 3/2011 e comprovado na NBR 11331, pelo método de espectrofotometria de absorção atômica é extremamente baixo, $0,07 \mathrm{mg} . \mathrm{kg}^{-1}$, enquanto o etanol hidratado não possui limite quanto à presença deste.

A limitação extremamente baixa do teor de cobre em EAC é justamente por este elemento estar instintivamente ligado à propriedade catalítica em reações oxidativas (Lehninger, 2004; Taylor \& Synovec, 1993), o que deve ser reportado por qualquer indústria ou estabelecimento comercial para evitar perdas.

Neste contexto, existem algumas tecnologias empregadas para a remoção deste íon como o uso de adsorventes. A exemplo disto, amêndoa de Baru (Dypterix alata) foi empregada como adsorvente de $\mathrm{Cu}$ (II) em etanol (Figura 4) e apresentou resultado significativo $\left(5,61 \mathrm{mg}^{-1} \mathrm{~g}^{-1}\right)$ em $\mathrm{pH}$ neutro e tempo de contato de 45 min (Mosquetta, 2010).

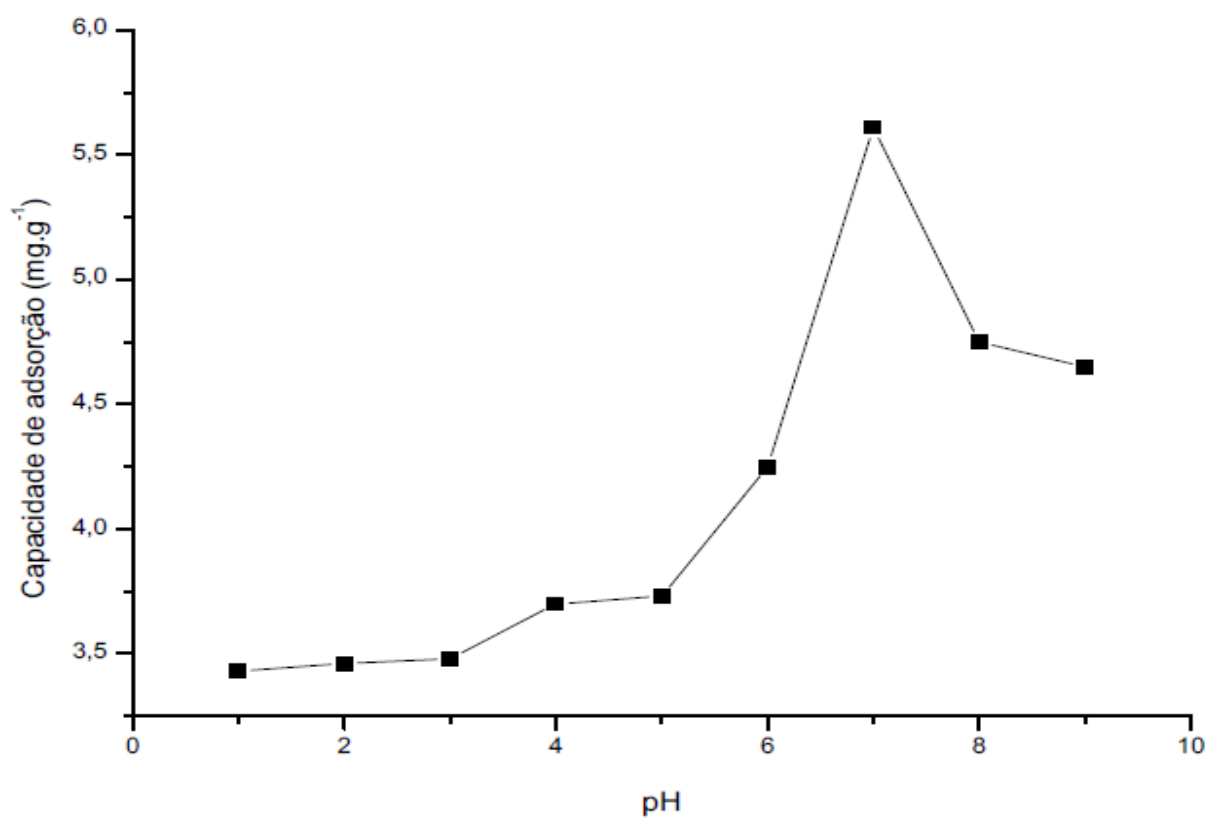

Figura 4 - Capacidade de adsorção de Cu (II) em etanol hidratado por amêndoa de Baru. Fonte: Adaptado de Mosquetta (2010).

A diminuição do $\mathrm{pH}$ também pode ser observada quando a presença de cobre é significativa, tendo em vista que este, através da faculdade de oxidação, leva ao aumento do teor hidrogeniônico do meio, liberado do etanol por meio de oxidação térmica, por exemplo (Karim-Nezhad et al., 2011). $\mathrm{O}$ teor de sulfatos e cloretos contidos no etanol combustível devem respeitar o limite máximo de 4 mg.kg-1 e 1 mg. $\mathrm{kg}^{-1}$ respectivamente, sendo quantificado a partir da NBR 10894 (1990) que determina a utilização da técnica cromatográfica de íons.

Segundo o White Paper (2007), a especificação quanto à presença de sulfatos só é obrigatória em relação ao etanol anidro combustível. Porém, pelo fato de que o etanol anidro é produzido a partir de etanol hidratado, a realização dos testes também se aplicaria a este último. Vale ressaltar que estes testes devem estar contidos no Certificado de Qualidade do produto e devem ser realizados quinzenalmente pelo fornecedor, e não por toda a cadeia de transporte e comercialização.

Com base em Kousi e demais colaboradores (2011), a presença de íons sulfato em etanol pode promover a reação de oxidação completa ou incompleta por bactérias redutoras de sulfato, fazendo 
com que o produto de interesse industrial seja transformado em acetato, ácido sulfídrico e água (incompleta), ou totalmente em $\mathrm{CO}_{2}$ (completa).

A presença de íons sulfato e íons cloreto em etanol hidratado favorecem, por meio da oxidação, a corrosão de tanques, equipamentos e sistemas automotores, visto que o ácido sulfídrico liberado é altamente corrosivo (Pereira et al., 2004).

Os íons cloreto são extremamente corrosivos devido ao seu tamanho ser bastante reduzido se comparado a diversos outros íons, o que facilita sua mobilidade em soluções líquidas e até mesmo sólidas (Cao et al., 2013). Lou e Singh (2010) verificaram que o cloreto é capaz de aumentar significativamente a corrosão de materiais como aço-carbono em etanol.

Controlados pelas NBR 10422 e NBR 11331, os limites detectados por fotometria de chama e espectrofotometria de absorção atômica devem ser inferiores a $2 \mathrm{mg} \cdot \mathrm{kg}^{-1}$ e $5 \mathrm{mg} \cdot \mathrm{kg}^{-1}$, quando em análise de sódio e ferro em etanol, respectivamente. Estes limites somente são obrigatórios ao fornecedor de etanol anidro combustível, mas segundo a ANP (2011b), nada impede que os demais agentes da cadeia os realizem para etanol anidro e também hidratado.

Vale ressaltar, que quando o ferro é encontrado em níveis superiores ao determinado pela ANP, observa-se a formação de depósitos no interior da câmara de combustão, diminuindo o tempo de vida útil dos motores (ANP, 2011).

Gomas tratam-se de um conjunto de polissacarídeos de origem vegetal ou microbiana, que em soluções aquosas tendem a formar géis e/ou suspensões viscosas que se agregam formando depósitos (Whistler, 1993).

Com um limite máximo de $5 \mathrm{mg} .100 \mathrm{~mL}^{-1}$, a ANP delimita este valor baseado na D381 da ASTM. Conforme Koehler (2006), gomas são formadas durante a armazenagem de combustível, que pode levar ao depósito nas superfícies do sistema de indução, válvulas de admissão, caules e guias de motores. Este método é composto por uma etapa de lavagem da amostra com n-heptano (P.A.), um composto que atua na remoção do resíduo da evaporação proveniente de componentes não voláteis contidos no etanol (Souza et al., 2004).

Visto que o etanol pode conter inúmeros constituintes ácidos originados nas etapas da fermentação, transporte e manuseio do produto, a determinação da acidez total do produto é necessária a fim de delimitar a qualidade do produto e descartar possíveis lotes incompatíveis (INMETRO, 2011). Sendo assim, com base na NBR 9866 (2006), a ANP delimita o limite máximo de $30 \mathrm{mg}$ de ácido acético $\mathrm{L}^{-1}$ que é calculada a partir de titulação com solução padrão de hidróxido de sódio.

$\mathrm{O} \mathrm{pH}$, que também está diretamente ligado à acidez do etanol, deve ser resguardado em faixa variável de 6 a 8, somente para EHC e deve seguir os métodos vigentes da NBR 10891 (2011b). Por estar relacionado, principalmente à quantidade de ácidos fortes, que são gerados tanto na etapa de fermentação viável e pelos contaminantes, quanto de destilação. É facilmente interpretado como grau de corrosão de tanques e motores, sendo importante parâmetro a se monitorar visando prolongar a vida útil destes (Gonçalves et al., 2011).

\section{CONCLUSÕES}

Visto que a produção de bioetanol é inerente a diversas variáveis que interferem em sua qualidade, avaliou-se indispensável um controle rigoroso da sua produção e comercialização, para garantir maior confiabilidade aos consumidores e competitividade entre mercados nacionais e internacionais. A não conformidade com as exigências previstas pela ANP pode gerar problemas na combustão, diminuindo a eficiência e vida útil do motor.

\section{REFERÊNCIAS}

ABNT NBR 10547, Álcool etílico - Determinação da condutividade elétrica. Associação Brasileira de Normas Técnicas, 1988.

ABNT NBR 10894, Álcool etílico - Determinação de íons cloreto e sulfato por cromatografia iônica. Associação Brasileira de Normas Técnicas, 1990. 
ABNT NBR 13993, Álcool etílico combustível - Determinação do teor de gasolina. Associação Brasileira de Normas Técnicas, 2002.

ABNT NBR 5992, Álcool etílico e suas misturas com água - Determinação da massa específica e do teor alcoólico - Método do densímetro de vidro. Associação Brasileira de Normas Técnicas, 2008.

ABNT NBR 9866, Álcool etílico - Determinação da acidez total. Associação Brasileira de Normas Técnicas , 2006.

ABNT NBR ISO 9000, Sistemas de Gestão de Qualidade - Fundamentos e Vocabulário. Associação Brasileira de Normas Técnicas, 2006.

ANP. Agência Nacional do Petróleo, Gás Natural e Biocombustíveis - Regulamento Técnico nº 3/2011a.

ANP. Agência Nacional do Petróleo, Gás Natural e Biocombustíveis - Resolução ANP Nº 7/2011b.

BALLESTERO-ALVAREZ, M. E. (Coord.). Administração da qualidade e da produtividade: abordagens do processo administrativo. São Paulo: Atlas, 2001. 488p.

BARBARÁ, S.; et al. (Org.). Gestão por processos: fundamentos, técnicas e modelos de implementação: foco no sistema de gestão da qualidade com base na ISO 9000:2000. Rio de Janeiro: Qualitymark, 2006. 305p.

CAO, L.; FRANKEL, G. S.; SRIDHAR, N. Effect of chloride on stress corrosion cracking susceptibility of carbon steel in simulated fuel grade ethanol. Eletrochimica Acta, v. 104, p. 255-266, 2013.

CAULCUTT, R. Statistical process control (SPC). Assembly Automation, v. 16, n. 4, p. 10-14, 1996.

CHIAVENATO, I. Administração nos novos tempos. $2^{\text {a }}$ Ed. Rio de Janeiro: Campus, 1999. p.710.

COELHO, S. T.; GOLDEMBERG, J.; LUCON, O. S.; GUARDABASSI, P. M. Etanol de cana brasileiro: lições aprendidas. Energia para o Desenvolvimento Sustentável, v. x, n. 2, p. 26-39. 2006.

CORTEZ, L. A. B. Biofuels-sugarcane ethanol: the Brazilian perspective. $3^{\text {rd }}$ Symposium on the Global Energy Future, 2010.

COSTA, A. F. B.; EPPRECHT, E. K.; CARPINETTI, L. C. R. Controle Estatístico de Qualidade. 2a Ed. São Paulo: Atlas, 2005.

FAO. Food and Agriculture Organization of the United Nations. FAOSTAT. Disponível em: $<$ http://faostat3.fao.org/faostat-gateway/go/to/home/E>. Acesso em: Mar/2014.

DAMINELLI, L. M. Análise do peso do biscoito laminado: aplicação do controle estatístico do processo. 2013. 55f. Trabalho de conclusão de Curso (Engenharia de Produção), Universidade Tecnológica Federal do Paraná. Medianeira-PR.

FELD, W. M. Lean manufacturing: tools, techniques, and how to use them. Ed. CRC, 248 p., 2000.

GOLDEMBERG, J.; COELHO, S. T.; GUARDABASSI, P. A sustentabilidade da produção de etanol a partir da cana. Política Energética, v. 36, p. 2086-2097, 2008.

GONÇALVES, M. A.; GONZAGA, F. B.; FRAGA, I. C. S.; et al. Avaliação de Laboratórios Brasileiros na Determinação de Alguns Parâmetros de Qualidade De Biocombustíveis. Química Nova, v. 36, n. 3, 393-399, 2013. 
GONÇALVES, M. A.; GONZAGA, F. B.; FRAGA, I. C. S. et al. Evaluation study of different glass electrodes by an interlaboratory comparison for determining the $\mathrm{pH}$ of fuel ethanol. Sensors and Actuators B: Chemical, v. 158, p. 327-332, 2011.

HANNY, B. da S.; REY-SÁNCHEZ, R. D. S. Viabilidade da certificação de qualidade iso 9001:2000 em usinas de açúcar e álcool de Uberaba-MG e região. FAZU em Revista, n. 6, p. 121-192, 2009.

INMETRO. Relatório Final da Comparação Interlaboratorial de Acidez Total em Etanol por Titulação Potenciométrica Automatizada. Comitê técnico: Carla de Matos Ribeiro, Fabiano Barbieri Gonzaga, Isabel Cristina Serta Fraga et al., 2011.

KARIM-NEZHAD, G.; DIZAJDIZI, B. Z.; DORRAJI, P. S. Oxidação eletrocatalítica de etanol em brometo de cobre modificada eletrodo de cobre em comparação com eletrodos de cobre modificados nuas e cloreto de cobre. Comunicações Catálise, v. 12, p. 906-909, 2011.

KOEHLER, Instruments. Catalog: fuels. Disponível em: < http://www.koehlerinstrument.com/literature/ catalog/2006/05-Fuels.pdf>. Acesso em: Jul/2013.

KOUSI, P.; REMOUNDAKI, E.; HATZYIKIOSEYIAN, A.; et al. Metal precipitation in an ethanol-fed, fixed-bed sulphate-reducing bioreactor. Journal of Hazardous Materials, v. 189, p. 677-684, 2011.

LOU, X.; SINGH, P. M. Role of water, acetic acid and chloride on corrosion and pitting behaviour of carbon steel in fuel-grade ethanol. Corrosion Science, v. 52, n. 7, p. 2303-2315, 2010.

LEHNINGER, A. L.; DAVID, N. L.; COX, M. M. Lehninger Principles of Biochemistry. $4^{\mathrm{a}}$ ed., W. H. Freeman \& Company, 2004.

MARSHALL JUNIOR, I.; et al. Gestão da qualidade. $8^{\text {a }}$ Ed. Rio de Janeiro: FGV, 2006. p.196.

MONTGOMERY, D. C. Introduction to statistical quality control. 4ª Ed. New York: John Wiley, 2001.

MOSQUETTA, R. Remoção de cobre em álcool etílico hidratado combustível utilizando amêndoaa de Baru (Dypterix alata). 2010. 65f. Dissertação (Mestrado em Química), UFU, Uberlândia-MG.

OLIVEIRA, S. M. de.; AZEVEDO, D. B. de.; CENTENARO, M. et al. Certificação da Indústria do Etanol Brasileiro no Contexto dos Stakeholders. Revista em Agronegócios e Meio Ambiente, v. 5, n. 2, p. 283-309, 2012.

OLIVEIRA, T. S.; LIMA, R. H. P. Aplicação do controle estatístico de processo na mensuração da variabilidade em uma usina de etanol. INGEPRO - Inovação, Gestão e Produção, v. 3, n. 6, 2011.

PEREIRA, E. A.; STEVANATO, A.; CARDOSO, A. A.; TAVARES, M. F. M. Indirect determination of chloride and sulfate ions in alcohol fuel by capillary electrophoresis. Analytical and Bioanalytical Chemistry, v. 380, p. 178-182, 2004.

SATOLO, E. G.; SIMON, A. T. Nível de utilização de práticas da qualidade no complexo sucroalcooleiro. XXVII Encontro Nacional de Engenharia de Produção, Foz do Iguaçu-PR, 2007.

SOARES, V. L. M. P. Aplicação e implantação do controle estatístico de processo em pintura industrial. 2003. 114f. Dissertação de Mestrado. Programa de Pós-Graduação em Engenharia de Produção. Universidade Federal de Santa Catarina.

SOBRINHO, P. Processo (simplificado) de produção de ETANOL de MILHO. Companhia Nacional de Abastecimento Superintendência Regional de Mato Grosso - CONAB, 2012. 
SOUZA, J. C.; COSTA, J. L. O.; LIM, A. A. G. de. et al. Validação do Uso do n-heptano Recuperado na Análise de Goma Lavada em Gasolina Automotiva. Revista Analytica, n. 9, 2004.

TAYLOR, D. B.; SYNOVEC, R. E. Chromatographic Determination of Copper Speciation in Jet Fuel. Talanta, v. 40, n. 4, p. 495-501, 1993.

UNICA. União da Indústria de Cana-de-açúcar. Final report of 2012/2013 harvest season South-Central region. Dez/2013.

VIEIRA, S. M. Estatística para a Qualidade. Rio de Janeiro: Elsevier, 1999.

WHISTLER, R. L. Industrial gums: polysaccharides and their derivatives. Cap.1: Intoduction to industrial gums, $3^{\text {a }}$ ed., p. 1-19, 1993.

WHITE PAPER ON INTERNATIONALLY COMPATIBLE BIOFUEL STANDARDS. Tripartite Task Force: Brazil, European Union \& United States of America. 2007. Disponível em: <www.inmetro.gov.br/ painelsetorial/biocombustiveis/whitepaper.pdf>. Acesso em: Jul/2013

XIE, M.; GOH, T.N. Statistical techniques for quality. The TQM Magazine, v. 1, n. 4, p. 238-241, 1999.

ZAFALON, M. Etanol vindo do milho é viável no Brasil. Folha De São Paulo, 2012. 